\title{
Dermatan sulfate activates nuclear factor- $k b$ and induces endothelial and circulating intercellular adhesion molecule-1
}

\author{
Stanley F. Penc, ${ }^{1}$ Bohdan Pomahac, ${ }^{2}$ Elof Eriksson, ${ }^{2}$ Michael Detmar, ${ }^{3}$ \\ and Richard L. Gallo ${ }^{1}$ \\ ${ }^{1}$ Department of Dermatology and Division of Development and Newborn Medicine, Boston Children's Hospital \\ and Harvard Medical School, Boston, Massachusetts 02115-5737, USA \\ ${ }^{2}$ Division of Plastic Surgery, Boston Children's Hospital and Brigham and Women's Hospital, Harvard Medical School, \\ Boston, Massachusetts 02115-5737, USA \\ ${ }^{3}$ Cutaneous Biology Research Center, Harvard Medical School, Charlestown, Massachusetts, 02129 USA
}

Address correspondence to: Richard L. Gallo, Harvard Medical School, Boston Children's Hospital, 300 Longwood Avenue, Enders 961, Boston, Massachusetts 02115-5737, USA. Phone: (617) 355-7678; Fax: (617) 713-4340; E-mail: Gallo@A1.Tch.Harvard.edu

Received for publication July 29, 1998, and accepted in revised form March 23, 1999.

Proteoglycans (PGs) can influence cell behaviors through binding events mediated by their glycosaminoglycan (GAG) chains. This report demonstrates that chondroitin sulfate B, also known as dermatan sulfate (DS), a major GAG released during the inflammatory phase of wound repair, directly activates cells at the physiologic concentrations of DS found in wounds. Cultured human dermal microvascular endothelial cells exposed to DS responded with rapid nuclear translocation of nuclear factor- $\kappa \mathrm{B}(\mathrm{NF}-\kappa \mathrm{B})$, increased expression of intercellular adhesion molecule-1 (ICAM-1) mRNA, and increased ICAM-1 cell surface protein. Heparan sulfate and chondroitin sulfates A and $C$ had no effect on activation of NF- $\kappa B$ or induction of ICAM-1. Inhibition of NF- $\kappa B$ activation blocked the effect of DS. The increase in cell surface ICAM-1 did not involve TNF- $\alpha$ or IL-1 release by endothelial cells, but it was facilitated by autocrine factors whose release was initiated by DS. The ICAM-1-inductive activity of DS was confirmed in vivo. Injection of DS, but not heparin or other chondroitin sulfates, into mice greatly increased circulating levels of soluble ICAM. These data provide evidence that DS, but not other GAGs, initiates a previously unrecognized cell signaling event that can act during the response to injury.

J. Clin. Invest. 103:1329-1335 (1999).

\section{Introduction}

Glycosaminoglycans (GAGs) regulate the activity of multiple molecules in the extracellular environment by binding to proteins such as growth factors, enzymes, enzyme inhibitors, and components of the extracellular matrix (1-3). Observations made during wound healing have shown that proteoglycans (PGs), such as syndecan-1 and -4 , are induced during the initial stages of repair (4-7). The increased expression of PGs and their associated GAGs enables them to act as a central mechanism for control of multiple cell behaviors important to the repair process (8). Several reports have shown that heparan sulfate is necessary for the function of heparin-binding ligands, such as members of the fibroblast growth factor (FGF) family $(9,10)$. Dermatan sulfate (DS) GAGs have also been found to bind heparin-binding growth factors, including FGF-2 (4), hepatocyte growth factor/scatter factor (11), heparin cofactor-II $(12,13)$, platelet factor-4 (14), fibronectin (15), and protein C inhibitor (16). In human wounds, DS contributes the majority of FGF2 -dependent cell responsiveness, with heparan sulfate having lesser activity (4).

The early response to injury, during which DS is released, is associated with a large inflammatory cell infiltrate. Intercellular adhesion molecule-1 (ICAM-1, or CD54) is a member of the immunoglobulin supergene family and plays an important role during inflammation by facilitating the tight adhesion of leukocytes to the vascular wall. ICAM-1 can be expressed on the surfaces of several cell types, including endothelial cells, epithelial cells, macrophages, and fibroblasts (17). The expression of ICAM-1 increases dramatically during several cutaneous inflammatory disorders including, but not limited to, localized and systemic scleroderma (18-20) and Kawasaki's disease (21). Several agents have been demonstrated to increase ICAM-1 expression, but the mechanism responsible for induction during cutaneous inflammation has not been clearly defined.

In this investigation, we explore the ability of GAGs present in skin and released during wound repair to activate endothelial cells and to increase ICAM-1. We show that DS, but not other GAGs, has potent ability to activate endothelial cells and increase cell surface ICAM1 in vitro and circulating ICAM- 1 in vivo. These observations demonstrate direct signaling activity for GAG in skin and identify a previously unknown mechanism for cell activation.

\section{Methods}

Recombinant human TNF- $\alpha$ and mouse soluble ICAM-1 (sICAM-1) ELISA were purchased from Endogen Inc. (Woburn, Massachusetts, USA). Human ICAM-1 cDNA was kindly pro- 

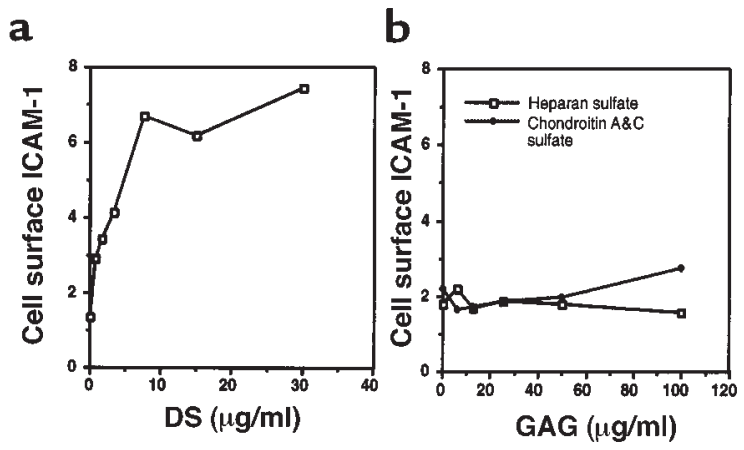

Figure 1

DS induces endothelial cell surface ICAM-1. Cell surface ICAM-1 was measured on human dermal microvascular endothelial cells by ELISA, as described in Methods. (a) Cellular response to 24-hour culture with various concentrations of pure DS in defined media containing $1 \%$ FCS. (b) Cells treated as described with heparan sulfate or chondroitin sulfates A and C. Data represent mean relative cell surface ICAM-1 expressed as mean $\mathrm{OD} / \mathrm{min} \pm \mathrm{SD}$ for triplicate determinations.

vided by Timothy Springer (Harvard Medical School). Antihuman CD54 (anti-ICAM-1; HA58) was from PharMingen (San Diego, California, USA), and alkaline phosphatase-conjugated goat anti-mouse IgG was from Cappel Research Products (Durham, North Carolina, USA). Anti-ISGF3y (antiSTAT1) was purchased from Transduction Laboratories (Lexington, Kentucky, USA), and CY3-conjugated goat antimouse IgG was from Caltag Laboratories Inc. (San Francisco, California, USA). BSA, chondroitin sulfate B lyase (chondroitinase B), porcine intestinal heparan sulfate, chondroitin sulfate $\mathrm{ABC}$, and heparin were from Sigma Chemical Co. (St. Louis, Missouri, USA). Porcine skin DS with a molecular weight range of $11-25 \mathrm{kDa}$ and determined pure by infrared spectroscopy was from Seikagaku America Inc. (Rockville, Maryland, USA).

Cell culture. Human dermal microvascular endothelial cells were purified from foreskin using magnetic beads coated with an anti-E-selectin mAb as described previously (22). Homogeneous cell populations were confirmed by morphology and expression of CD31 or vWF. Cells were grown in endothelial cell basal medium (Clonetics, Walkersville, Maryland, USA) supplemented with $1 \mu \mathrm{g} / \mathrm{mL}$ hydrocortisone acetate, $5 \times 10^{-5}$ M N6, 2' O-dibutyryl-adenosine 3' $: 5^{\prime}$ cyclic monophosphate (Sigma Chemical Co.), 20\% FCS (HyClone Laboratories, Logan, Utah, USA), $100 \mathrm{U} / \mathrm{mL}$ penicillin, and $100 \mu \mathrm{g} / \mathrm{mL}$ streptomycin. All experiments were performed using growtharrested, contact-inhibited postconfluent monolayers derived from cells at less than passage 7 .

Purification and analysis of wound fluid glycosaminoglycan. The use of human wound fluids collected within 24 hours of surgery was approved by The Human Research Committee of Brigham and Women's Hospital (protocol no. 92-5416-01). These materials were centrifuged at $300 \mathrm{~g}$ for 10 minutes to remove cells and debris, and wound fluid was adjusted to $\mathrm{pH} 4.5$ with Buffer A (150 mM NaCl, 2M urea, 0.5 M EDTA, 1 mM PMSF, 0.1\% Triton $\mathrm{X}-100,50 \mathrm{mM}$ sodium acetate; $\mathrm{pH} 4.5$ ). Solutions were applied at $4{ }^{\circ} \mathrm{C}$ to anion exchange columns (QAE Sephadex A25; Pharmacia Biotech Inc., Piscataway, New Jersey, USA), followed by consecutive washes with 10-bed volumes of Buffer $A$ and 10bed volumes of similar buffer containing $300 \mathrm{mM} \mathrm{NaCl}$. GAG was eluted with 3-bed volumes of similar buffer containing $2 \mathrm{M}$ $\mathrm{NaCl}$. Eluted material was precipitated twice with 3 volumes of $95 \%$ ethanol $/ 1.3 \%$ potassium acetate and reconstituted in $\mathrm{H}_{2} \mathrm{O}$. In some preparations, wound fluid glycosaminoglycan (WFGAG) was further purified by boiling for 10 minutes in $4 \mathrm{M}$

guanidine $\mathrm{HCl}$ buffer containing $1 \%$ Triton X-100, followed by separation using a cesium chloride density gradient. Sulfated GAG was measured in WFGAG samples using the sulfate-binding cationic dye dimethylmethylene blue, according to the instructions of the Blyscan Proteoglycan and GAG Assay System manufacturer (Accurate Chemical and Scientific Corp., Westbury, New York, USA). Accuracy of GAG quantitation was verified by carbazole assay, which does not rely on GAG sulfation.

Measurement of cell surface ICAM-1. For quantitative determination of endothelial cell surface ICAM-1, a modification of a whole-cell ELISA technique was used. Cells cultured in 96-well tissue culture plates and treated for various times with test reagents (see legends to Figures) were evaluated microscopically for a change in cell morphology or cell number and then fixed in $2 \%$ paraformaldehyde, blocked with $5 \%$ goat serum in Trisbuffered saline (TBS) (20 mM Tris, $150 \mathrm{mM} \mathrm{NaCl}$; $\mathrm{pH} 7.4)$, and incubated for 1 hour at room temperature with a 1:200 dilution of mouse mAb HA58 directed against human CD54 in TBS $/ 0.1 \%$ BSA. Cells were then washed 3 times for 5 minutes with TBS and incubated for 30 minutes with a 1:5,000 dilution of alkaline phosphatase-conjugated goat anti-mouse $\operatorname{IgG}$ in TBS $/ 0.1 \%$ BSA. After 3 washes with TBS, phosphatase activity was determined by measuring absorbance of a $1 \mathrm{mg} / \mathrm{mL}$ solution of $p$-nitrophenylphosphate (Sigma Chemical Co.) in $10 \mathrm{mM}$ Tris-HCl, $100 \mathrm{mM} \mathrm{NaCl}, 5 \mathrm{mM} \mathrm{MgCl}$ (pH 9.5) at $405 \mathrm{nM}$. Rates of change of absorbency were determined using a microplate reader (Molecular Dynamics Inc., Sunnyvale, California, USA). Phosphatase activity was compared between identically treated cells incubated with irrelevant mouse IgG. Specificity of ELISA was confirmed in separate experiments by Western blot.

For experiments in which DS was enzymatically digested before addition to endothelial cells and measurement of cell surface ICAM-1, WFGAG or commercial DS was treated for 4 hours at $37^{\circ} \mathrm{C}$ with $2 \mathrm{U}$ chondroitinase $\mathrm{B}$ (Seikagaku America Inc.) in $50 \mathrm{mM}$ Tris, $50 \mathrm{mM} \mathrm{NaCl}, 4 \mathrm{mM} \mathrm{CaCl}_{2}$ (pH 8.0). Specificity of digestion with chondroitinase $\mathrm{B}$ was confirmed both by attempted digestions of DS with heparatinase (Seikagaku America Inc.) or measurement of chondroitinase B activity against purified heparan sulfate. After enzyme treatment, undigested GAGs were precipitated with 3 volumes of $95 \%$ ethanol $/ 1.3 \%$ potassium acetate and reconstituted with $\mathrm{dH} 2 \mathrm{O}$.

For experiments requiring removal of DS from endothelial cell-conditioned media, cells were incubated with DS for the

$\mathbf{a}$

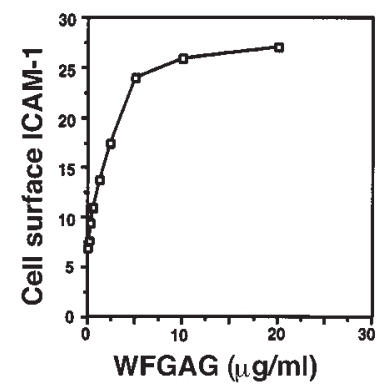

Figure 2

DS in wound fluid induces cell surface ICAM-1. Cell surface ICAM-1 was measured on human dermal microvascular endothelial cells by ELISA, as described in Methods. (a) Cells cultured for 24 hours with various concentrations of total soluble GAG purified from human wound fluids. (b) Control media, WFGAG $(4 \mu \mathrm{g} / \mathrm{mL})$, or pure DS $(20 \mu \mathrm{g} / \mathrm{mL})$ was treated with or without chondroitinase $\mathrm{B}$ (CHase $\mathrm{B})$, precipitated, and then added to endothelial cells cultured for 24 hours in defined media containing 1\% FCS. Data represents mean relative cell surface ICAM-1 content expressed as mean $\mathrm{OD} / \mathrm{min} \pm \mathrm{SD}$ for triplicate determinations. 


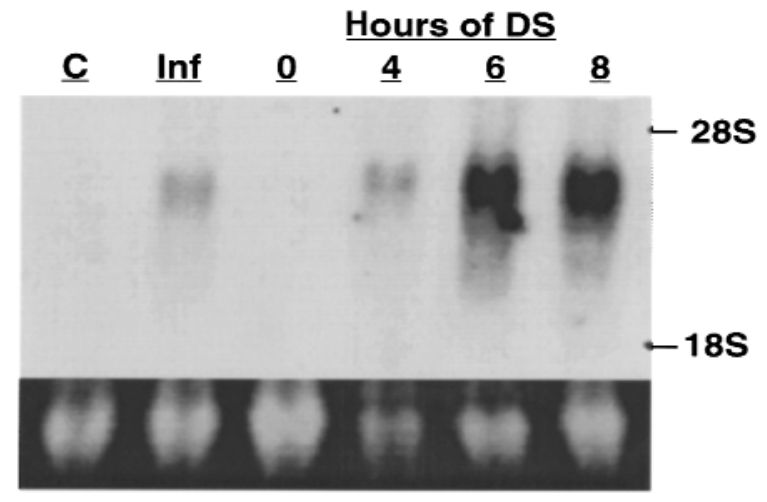

Figure 3

DS induces endothelial cell ICAM-1 mRNA. ICAM-1 mRNA was measured in human dermal microvascular endothelial cells by Northern analysis, as described in Methods. Ten micrograms of total RNA was analyzed from cells treated with media alone (lane C), $100 \mathrm{U} / \mathrm{mL}$ IFN- $\gamma$ for 8 hours, or $50 \mu \mathrm{g} / \mathrm{mL}$ pure DS for $0-8$ hours. Top panel shows results of probe specific for human ICAM-1, and bottom panel is ethidium bromide staining of $28 \mathrm{~S}$ RNA confirming similar loading amounts.

indicated times followed by collection of media. QAE Sephadex A25 beads equilibrated in PBS were added to these media samples and rocked for 1 hour at $4^{\circ} \mathrm{C}$. The samples were then gently centrifuged to separate the DS-bound beads from the conditioned media. Cell surface ICAM-1 was measured on fresh cells treated with these conditioned media by ELISA as already described here. Removal of DS was confirmed on parallel samples using dimethylmethylene blue detection. DS was removed from conditioned media by binding to $\mathrm{QAE}$ Sephadex beads rather than enzymatic digestion with chondroitinase B, because enzyme treatment only decreased ICAM1-inductive activity after ethanol precipitation of digested material. Conditioned media could not be used after ethanol precipitation and thus was depleted of DS by the described anion exchange procedure.

Northern blot analysis. Approximately $10 \mu \mathrm{g}$ of total RNA extracted from endothelial cell monolayers (23) was separated by electrophoresis through a $1 \%$ agarose/formaldehyde gel and transferred to Immobilon N (Millipore Corp., Bedford, Massachusetts, USA). Hybridization was carried out at $65^{\circ} \mathrm{C}$ in QuickHyb Solution (Stratagene, La Jolla, California, USA) using a random-primer-labeled 1.4-kb SalI-BglII fragment of human ICAM-1 cDNA. Filters were washed twice at room temperature for 15 minutes in $2 \times$ SSC/0.1\% SDS and twice in $0.2 \times$ SSC $/ 0.1 \%$ SDS at $55^{\circ} \mathrm{C}$. Data were collected by PhosphorImager (Molecular Dynamics Inc.).

Measurement of signal transducer and activator of transcription nuclear translocation. Endothelial cells grown on collagen-coated glass coverslips were fixed for 10 minutes at room temperature in $2 \%$ paraformaldehyde, followed by permeabilization for 2 minutes with $0.2 \%$ Triton X-100 in TBS. Cells were then blocked for 1 hour at room temperature with $1 \%$ goat serum in TBS $/ 0.1 \%$ BSA and incubated for an additional hour with antiISGF3 $\gamma$ directed against the signal transducer and activator of transcription (STAT) complex at a final dilution of 1:50 in TBS $/ 0.1 \%$ BSA. Cells were then washed 3 times with TBS and incubated with a 1:500 dilution of CY3-conjugated goat antimouse IgG. Immunofluorescence of cells was observed and photographed with a Zeiss Axiophot fluorescent photomicroscope.

Nuclear extracts and NF- $\kappa B$ electrophoretic mobility shift assay. The presence of nuclear factor- $\mathrm{\kappa B}(\mathrm{NF}-\mathrm{\kappa B})$ in endothelial cell nuclei was evaluated by modification of techniques described previously $(24,25)$. Endothelial cell cultures were placed on ice, har- vested by scraping with a rubber policeman, and 1.5 to $2 \times 10^{7}$ cells were resuspended in hypotonic lysis buffer $(10 \mathrm{mM}$ HEPES, $1.5 \mathrm{mM} \mathrm{MgCl}_{2}, 10 \mathrm{mM} \mathrm{KCl}$; pH 7.9) at $4^{\circ} \mathrm{C}$ for $20 \mathrm{~min}$ utes. Cells were then gently homogenized by 20 strokes with a loose-fitting Dounce homogenizer. Nuclei were collected by centrifugation for 4 minutes at $6,500 \mathrm{~g}$ and nuclear protein extracted with 3-pellet volumes of $20 \mathrm{mM}$ HEPES (pH 7.9), $25 \%$ (vol/vol) glycerol, $0.42 \mathrm{M} \mathrm{NaCl}, 1.5 \mathrm{mM} \mathrm{MgCl}_{2}$, and $0.2 \mathrm{mM}$ EDTA for 1 hour at $4^{\circ} \mathrm{C}$. Samples were then centrifuged for 5 minutes at $6,500 \mathrm{~g}$ and diluted in 3 volumes of $20 \mathrm{mM}$ HEPES (pH 7.9), $20 \%$ glycerol, $0.1 \mathrm{M} \mathrm{KCl}, 0.2 \mathrm{mM}$ EDTA, and $1 \%$ Nonidet P-40. All buffers contained freshly added protease inhibitors, $1.0 \mathrm{mM}$ phenylmethyl sulfonyl fluoride, $10 \mathrm{mM}$ DTT, and protease inhibitor cocktail used according to the manufacturer's instructions (Boehringer Mannheim Biochemicals, Indianapolis, Indiana, USA).

For shift assay, 2 oligonucleotides containing the NF- $\mathrm{\kappa B}$ binding sequence from the immunoglobulin $\kappa$ light chain gene enhancer were annealed (5'-AGCTCAGAGGGGACTTTCCGAGAG-3') (5'-AGCTCTCTCGGAAAGTCCCCTCTG-3') and end-labeled using Klenow (New England Biolabs Inc., Beverly, Massachusetts, USA) with $\left[\alpha-{ }^{32} \mathrm{P}\right] \mathrm{dATP}$ and $\left[\alpha-{ }^{32} \mathrm{P}\right] \mathrm{dCTP}(\mathrm{Du}$ Pont NEN Research Products, Boston, Massachusetts, USA). This probe was incubated with $10 \mu \mathrm{g}$ of nuclear extract for 45 minutes at room temperature in the presence of $2 \mu \mathrm{g}$ poly(dIdC) (Pharmacia Biotech Inc.) and $30 \mu \mathrm{g}$ BSA. Samples were electrophoresed on native $4 \%$ polyacrylamide gels.

Measurement of mouse circulating ICAM-1. Male C57 Black mice (The Jackson Laboratory, Bar Harbor, Maine, USA), weighing 25-30 g and maintained on food and water ad libitum, were injected intraperitoneally with $10 \mu \mathrm{g} / \mathrm{kg}$ soluble recombinant TNF- $\alpha, 1 \mathrm{mg}$ pure DS, or $4 \mathrm{mg}$ heparin or chondroitin sulfates A and C in sterile PBS. Blood samples were taken before injections and at 5 hours after injection. Serum

a

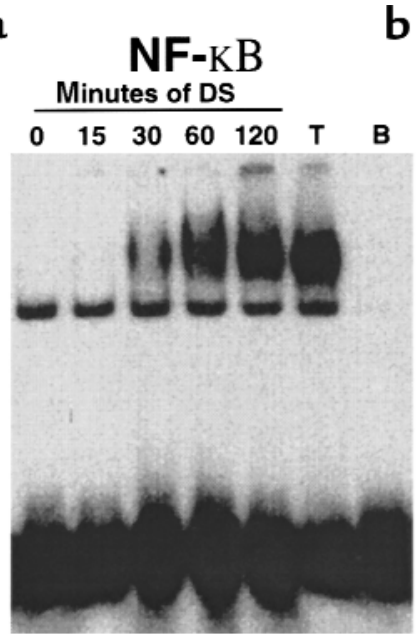

b STAT

Figure 4

DS activates NF-KB signaling. Activation of NF- $\mathrm{KB}$ and STAT signaling was measured by their translocation from endothelial cell cytosol to cell nuclei. (a) Measurement of NF- $\mathrm{KB}$ activation by electrophoretic mobility shift assay of nuclear extracts from endothelial cells treated for 0-120 minutes with $50 \mu \mathrm{g} / \mathrm{mL}$ pure DS, or 120 minutes with $2.5 \mathrm{ng} / \mathrm{mL}$ TNF- $\alpha$ (lane T). All extracts were mixed with ${ }^{32} \mathrm{P}$-labeled oligonucleotides containing the NF- $\mathrm{KB}$ binding site. The sample in lane B is identical to that in lane $T$, with the addition of a 50 -fold excess of unlabeled oligonucleotide. (b) Immunostaining of endothelial cells with antibody ISGF3 specific for the STAT complex. (1) Cells treated with media alone for 30 minutes. (2) Cells treated with $50 \mu \mathrm{g} / \mathrm{mL}$ pure DS for 30 minutes. (3) Cells treated with $100 \mathrm{U} / \mathrm{mL}$ IFN- $\gamma$ for 30 minutes. 


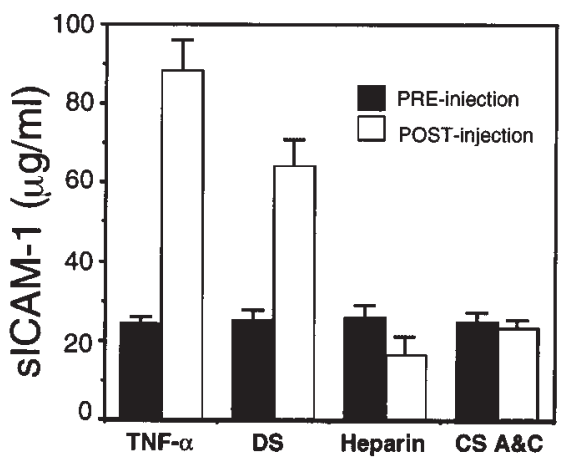

Figure 5

DS, but not other GAGs, induces circulating SICAM-1. SICAM-1 was measured in murine sera by ELISA, as described in Methods. Serum levels of sICAM- 1 were measured before or 5 hours after intraperitoneal injection of TNF- $\alpha(25 \mu \mathrm{g} / \mathrm{kg})$, pure DS (1 mg), heparin ( $4 \mathrm{mg})$, or chondroitin sulfates $A$ and $C(4 \mathrm{mg})$. Data represent mean \pm SD of triplicate measurements.

was isolated using Microtainer Serum Separator tubes (Becton Dickinson, Bedford, Massachusetts, USA), and sICAM-1 was measured by ELISA according to the instructions of the mouse sICAM-1 ELISA manufacturer (Endogen Inc.).

\section{Results}

Soluble DS increases ICAM-1 on endothelial cells. PGs are induced after injury and rapidly released into a soluble extracellular pool $(4,26,27)$. These events occur during the early inflammatory phase of wound repair. To determine whether the GAG associated with these PGs participates in the inflammatory process, endothelial cell expression of ICAM-1 was measured in the presence of various concentrations of pure GAG. Human dermal microvascular endothelial cells incubated for 24 hours with DS showed a dose-dependent increase in cell surface ICAM-1 expression (Figure 1a). No response was observed with chondroitin sulfates $A$ and $C$ or heparan sulfate (Figure 1b). The response to DS occurred with and without serum and without the addition of molecules known to affect ICAM-1 expression. No change in cell number or morphology was observed at any concentration or at any time during culture with DS or other GAGs.

Cell surface ICAM-1 was also induced when endothelial cells were cultured with total PG derived from wound fluid (Figure 2a). This effect occurred at the physiologic concentration of GAG normally present in wounds (4). To determine whether DS in wounds was responsible for ICAM-1 induction, WFGAG or pure DS was treated with chondroitinase B specifically to degrade DS. Undigested GAGs were then precipitated and analyzed for ability to induce ICAM-1. Figure $2 \mathrm{~b}$ demonstrates that DS was the ICAM-1-inducing molecule in WFGAG samples, as chondroitinase B treatment eliminated ICAM-1 induction.

DS increases ICAM-1 mRNA expression. Analysis of RNA from cells treated with DS demonstrated increased levels of ICAM-1 mRNA within 4 hours after treatment, with maximum expression observed after 6 hours (Figure 3 ). The magnitude of ICAM- 1 mRNA induced by DS exceeded that induced by IFN- $\gamma$. The requirement of RNA synthesis for ICAM-1 induction was confirmed in cells incu- bated with cordycepin before and during exposure to DS. Such treatment completely inhibited DS-induced ICAM1 cell surface expression (data not shown). Protein synthesis was also required for ICAM-1 induction because preincubation of cells with cycloheximide prevented this response (data not shown).

$D S$ induces nuclear localization of NF- $K B$. ICAM-1 transcription can be initiated through an NF- $\mathrm{KB}$ signal transduction pathway such as occurs in the presence of TNF- $\alpha$ (28). Measurement of nuclear translocation of $\mathrm{NF}-\kappa \mathrm{B}$ in endothelial cell nuclear extracts after treatment with DS demonstrated increased localization in cell nuclei within 30 minutes (Figure 4a). The degree of $\mathrm{NF}-\mathrm{kB}$ detected in nuclear extracts was similar in magnitude to that induced by TNF- $\alpha$. Treatment of cells with a specific inhibitor of NF- $\kappa B$ activation, pyrrolidine dithiocarbamate (PDTC) (29), abolished induction of ICAM-1 by DS (data not shown). Induction of ICAM-1 can also be mediated by the STAT signal transduction system. In contrast to NF-kB, DS was ineffective in activating STAT signaling, as evidenced by the lack of nuclear localization in cells incubated with DS (Figure $4 b)$. As control, IFN- $\gamma$ readily induced nuclear translocation of STAT (Figure 4b, panel 3). STAT nuclear translocation was detected as soon as 5 minutes after IFN- $\gamma$ exposure but at no time up to 120 minutes after treatment of cells with DS.

DS induces circulating ICAM-1 (sICAM-1) in vivo. The finding that DS induced ICAM-1 expression on endothelial cells in culture led us to evaluate whether DS could also induce ICAM-1 in vivo. To test this, circulating levels of DS were first measured in mice after its intraperitoneal injection. Before injection, no GAG was detected. However, 1 hour after a single 4-mg intraperitoneal injection, serum DS increased to approximately $90 \mu \mathrm{g} / \mathrm{mL}$. This circulating DS was rapidly eliminated and demonstrated a half-life in sera of approximately 7 hours. Having thus confirmed delivery of DS, sICAM-1 was measured in response to DS injection. sICAM-1 increased within 5 hours after administration of DS, or TNF- $\alpha$ as control (Figure 5). However, heparin and chondroitin sulfates $\mathrm{A}$ and $\mathrm{C}$ were ineffective as ICAM1 -inducing molecules, thus confirming the in vitro finding that only GAG in the form of DS induces ICAM-1. In kinetic experiments, a single injection of DS induced maximal ICAM-1 expression by 5 hours, with levels remaining elevated at 24 hours (data not shown). Similar kinetics were observed for TNF- $\alpha$, confirming prior reports of ICAM-1 induction by this cytokine (30). Although the degree of sICAM-1 induced by DS and TNF- $\alpha$ was similar, no change in behavioral activity was observed between DS-injected mice and controls, whereas a characteristic decrease in activity was seen in mice injected with TNF- $\alpha(30)$.

DS stimulates release of an autocrine ICAM-1-stimulating factor. The increase in ICAM-1 on endothelial cells after DS exposure was time dependent. In the continuous presence of DS, ICAM-1 increased after a total of 6 hours and remained elevated for at least 48 hours (Figure 6a). However, cells exposed to DS for various times and then washed and cultured for a total of 24 hours showed that only 1 hour of DS treatment was sufficient to commit 

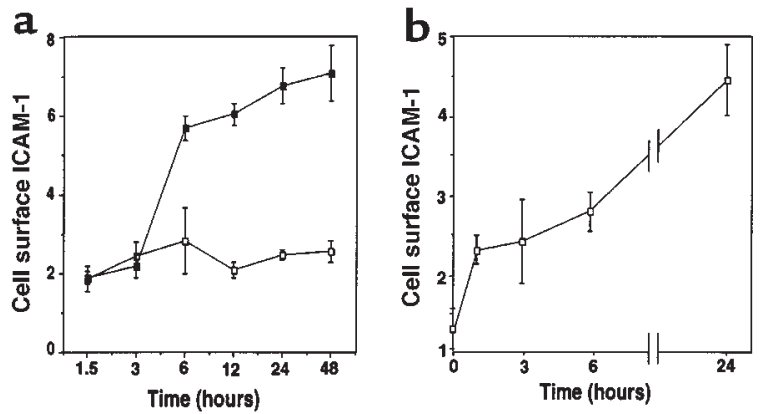

Figure 6

Pulse DS stimulation commits endothelial cells to ICAM-1 expression. Cell surface ICAM-1 was measured on human dermal microvascular endothelial cells by ELISA, as described in Methods. (a) Cells were cultured for the indicated times with $50 \mu \mathrm{g} / \mathrm{mL}$ DS in defined media containing 1\% FCS. (b) Cells were cultured as described for the indicated times followed by removal of the media, rinsing of cells 2 times with fresh media, and incubation for the duration of a 24-hour period with media lacking DS. Thus, each time point in graph (b) represents a total incubation time of 24 hours, with DS present for the indicated times. Data in $\mathbf{a}$ and $\mathbf{b}$ represent mean relative cell surface ICAM- 1 expressed as mean $\mathrm{OD} / \mathrm{min} \pm \mathrm{SD}$ for triplicate determinations.

cells to ICAM-1 induction (Figure 6b).

To determine whether this increase in ICAM-1 could be mediated by a factor(s) released into the media after exposure to DS, endothelial cells were first incubated with DS for various times, and the media conditioned by cells were then depleted of DS by anion exchange. Complete removal of DS was confirmed by dimethylmethylene blue detection (data not shown) and by ICAM-1-induction experiments done with media that were not conditioned by endothelial cells to which DS was added and subsequently removed by anion exchange in a manner identical to that for conditioned media. These DS-depleted media that were, or were not, conditioned by cells were then added to fresh endothelial cells for 24 hours to evaluate ICAM- 1 induction. Media conditioned for only 1 hour in the presence of DS contained ICAM-1-inductive activity, but conditioned media from cells not treated with DS showed no ICAM-1-inducing activity at any time point (Figure $7 \mathrm{a}$ ). Thus, autocrine activity was released into the media before the appearance of ICAM-1 (Figure 6a) but coincident with the commitment to ICAM-1 expression (Figure 6b).

To evaluate whether this autocrine activity in DSstimulated, endothelial cell-conditioned media was TNF- $\alpha$ or IL-1, ICAM- 1 induction was measured after treatment of conditioned media with neutralizing antibody to each cytokine. These antibodies had no effect on the ability of DS, or DS-depleted conditioned media, to induce ICAM-1 (Figure $7 \mathrm{~b}$ ). The inhibitory activity of these antibodies was confirmed in separate experiments using recombinant TNF- $\alpha$ and IL-1 (data not shown).

\section{Discussion}

The presence of PGs or GAGs at cell surfaces and in the extracellular space enables cells to respond to a wide variety of signaling molecules (2). Among the GAGs, heparan sulfate has been most widely studied. Heparan sulfate can act by enabling the activity of growth fac-

tors such as members of the FGF family $(9,10)$ or by modifying the action of enzymes such as antithrombin III (31) and matrix metalloproteases (32). The results presented here show that another GAG, DS, also has potent biologic activity. Unlike heparan sulfate, however, DS activates endothelial cells in the absence of supplemental costimulatory molecules such as cytokines or growth factors. DS increased cell surface ICAM-1, increased ICAM-1 mRNA, and was a potent activator of nuclear translocation of NF- $\mathrm{kB}$. The activity of DS was also observed in vivo. A large increase in circulating ICAM-1 was induced in mice after intraperitoneal injection of DS. These data indicate that DS present in skin or released following injury can directly signal local or distant cellular events important for inflammation and wound repair.

The ability of DS to induce endothelial cell ICAM- 1 is unique among the GAGs. Pure DS induced cell surface ICAM-1 in a dose-dependent manner at or below the concentrations of DS that are found in vivo (4). Contaminating proteins in DS preparations were not likely to be responsible for this effect, as the material was found to be pure by infrared spectroscopy. Furthermore, digestion with chondroitinase B, an enzyme specific for DS, eliminated ICAM-1-inductive activity. Similar to pure DS, total GAGs from human surgical wounds also induced ICAM-1. The presence of contaminating ICAM1 -inducing molecules was also not likely in these samples, as the material was boiled in $4 \mathrm{M}$ guanidine and purified by cesium chloride density centrifugation. Chondroitinase B treatment also eliminated ICAM-1 induction from wound GAGs, thus confirming that DS in wounds was the active molecule. This activity likely

a
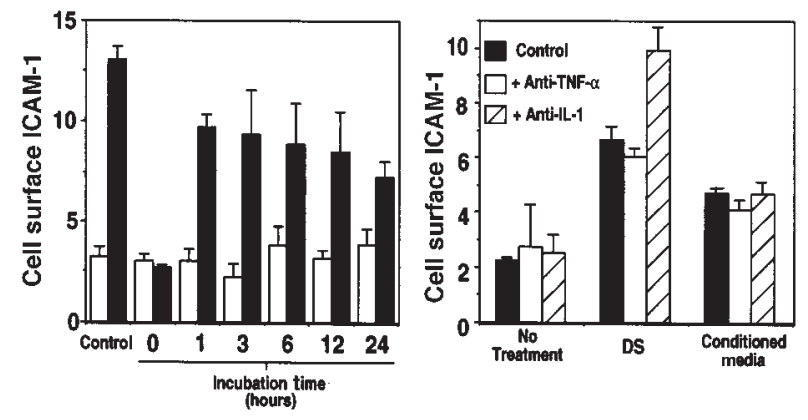

Figure 7

DS initiates autocrine induction of cell surface ICAM-1. Cell surface ICAM1 was measured on human dermal microvascular endothelial cells by ELISA, as described in Methods. (a) Cells were cultured for the indicated times in media (open bars) or media containing $50 \mu \mathrm{g} / \mathrm{mL}$ DS (filled bars). These media were then depleted of DS by anion exchange, followed by addition to fresh cells for 24 hours. Bars labeled "control" represent cells cultured continuously for 24 hours. (b) Effect of neutralizing antibodies to TNF- $\alpha$ or IL- 1 on ICAM- 1 induction by media alone (no treatment), 50 $\mu \mathrm{g} / \mathrm{mL} \mathrm{DS}$, or conditioned media from cells treated for 24 hours with DS and then depleted of DS as described in a (conditioned media). Media were pretreated in the absence or presence of $5 \mu \mathrm{g} / \mathrm{mL}$ anti-TNF- $\alpha$ or 10 $\mu \mathrm{g} / \mathrm{mL}$ anti-IL-1 and then added to endothelial cell culture for 24 hours before assay. Data represent mean relative cell surface ICAM-1 expressed as mean $\mathrm{OD} / \mathrm{min} \pm \mathrm{SD}$ for triplicate determinations. 
resulted from the unique disaccharide composition and/or sulfation patterns of DS. Future compositional analysis will elucidate the specific determinants in DS that are responsible for activity.

The finding that intraperitoneal administration of DS augmented circulating sICAM-1 demonstrated that this GAG can function in vivo and confirmed our in vitro data that DS induces ICAM-1. Mice administered other GAGs showed no response, again demonstrating the specificity of this response for DS. The rapid response to injected DS, and lack of induction by other GAGs suggest that in vivo activity was not from secondary inflammation of the peritoneum or gut. Although these data do not show the mechanism by which ICAM-1 is shed in vivo, the origin of sera sICAM-1 could have been from several tissue sources including skin, lung, liver, or spleen. Experiments performed by injection of TNF- $\alpha$ into mice have suggested that several organs can contribute to the release of sICAM-1, with the spleen functioning as a major contributor (30). Our data show that sICAM-1 is not detectable from endothelial cells stimulated by DS in vitro. It remains to be determined whether circulating sICAM-1 in the mouse is derived from a small contribution of the large available endothelial surface area in vivo or from an increased contribution from specific tissues.

After TNF- $\alpha$ injection into mice, these animals displayed a dramatic decrease in activity that was not seen after DS injection. This behavioral difference is not due to a difference in the in vivo kinetics of DS ICAM-1 responsiveness, as these are similar to those of TNF- $\alpha$. Differences in in vivo activity may reflect different target cells and/or tissues or a difference in cellular responsiveness despite similarities in NF- $\kappa B$ activation and ICAM1 induction. Such differences in physiologic responsiveness between DS and cytokines suggest that the effects of DS on inflammatory responses are more limited. These inflammatory events may be similar to the response observed during wound repair. The amount of DS capable of inducing ICAM-1 is comparable to concentrations observed for DS in human wound fluids. Therefore, DS can act in vivo and is released in sufficiently high concentrations to function as a participant in the initiation of inflammation after injury.

A hypothetical mechanism by which DS activates endothelial cells can be proposed from our data. DS activated endothelial cell NF-KB within 30 minutes. Furthermore, inhibition of NF- $\mathrm{KB}$ signaling by PDTC blocked DS-induced ICAM-1, thus suggesting that DS increases ICAM-1 through NF- $\kappa$ B. It was unclear, however, whether these effects of DS were direct or mediated through an intermediate autocrine factor(s). Conditioned media from cells treated with DS for as little as 1 hour contained substantial ICAM-1-inductive activity. This demonstrates the presence of another ICAM1 -inducing molecule(s) that was rapidly initiated by DS. Cells treated with a pulse of DS for only 1 hour also increased ICAM-1. The lesser ICAM-1-inducing activity of conditioned media or pulse treatment suggests that DS may partially activate ICAM-1 expression directly, that DS-treated cells continue to produce the autocrine factor(s) into the media after removal of DS, or that treatment of conditioned media by anion exchange to remove DS affects other components of the media that act on ICAM-1 responsiveness. These actions of DS, or DS-conditioned media, were not via the cytokines TNF$\alpha$ or IL- 1 , both known stimulators of ICAM- 1 induction via NF- $\mathrm{KB}$. Other potential mechanisms of cell stimulation of NF-kB, such as contaminating hyaluronic acid or lipopolysaccharide (33), are also not likely, as treatment of DS and WFGAG with chondroitinase B and ethanol precipitation completely inhibited ICAM-1 induction, and the purification procedure used to isolate these GAGs would eliminate hyaluronic acid, other anionic compounds, or temperature-sensitive proteins. Therefore, although it is unclear whether DS functions through a direct or indirect mechanism, it is clear that it has a potent capacity to activate NF- $\mathrm{KB}$ and lead to increased ICAM-1 expression in vitro and in vivo .

The activation of endothelial cells by DS has important implications for understanding the normal response to tissue damage. DS is present in skin as a large insoluble extracellular pool (34). We demonstrate here that the soluble form of this material stimulates expression of ICAM-1. ICAM-1 has been found to be abundantly expressed in cutaneous disease such as scleroderma (18-20), which is also characterized by an increase in DS (35-37). It is attractive to speculate that DS released from the dermis may contribute to such disease processes by inducing ICAM-1. This inflammatory pathway would be independent of late events requiring cytokine delivery and can occur immediately upon exposure of cells to the DS released from the extracellular matrix. Thus, stimulation by DS may be a previously unrecognized mechanism for direct cell activation in various diseases and following trauma, and is a redundant system acting with cytokines for initiating leukocyte adhesion by ICAM-1. Our current understanding of wound repair has shown that such redundancy is an important part of the response to injury. Recognition of cell activation by DS presents a new pathway for investigation of therapy in abnormal repair and inflammatory processes in general.

\section{Acknowledgments}

This work was supported by National Institutes of Health (NIH) grant AR-44379, grants from the American Skin Foundation and the American Society for Dermatologic Surgery (to R.L. Gallo), and NIH training grant T32-AR07098-24 (to S.F. Penc).

1. Schlessinger, J., Lax, I., and Lemmon, M. 1995. Regulation of growth factor activation by proteoglycans: what is the role of the low affinity receptors? Cell. 83:357-360

2. Bernfield, M., et al. 1992. Biology of the syndecans: a family of transmembrane heparan sulfate proteoglycans. Annu. Rev. Cell Biol. 8:365-398.

3. Ruoslahti, E., and Yamaguchi, Y. 1991. Proteoglycans as modulators of growth factor activities. Cell. 64:867-869.

4. Penc, S.F., et al. 1998. Dermatan sulfate released after injury is a potent promoter of FGF-2 activity. J. Biol. Chem. 273:28116-28121.

5. Gallo, R.L., Kim, C., Kokenyesi, R., Adzick, N.S., and Bernfield, M. 1996. Syndecans- 1 and -4 are induced during wound repair of neonatal but not fetal skin. J. Invest. Dermatol. 107:667-683.

6. Gallo, R.L., Siebert, E., Kim, C., and Bernfield, M. 1994. The syndecans, co-receptors for matrix and growth factors are selectively expressed in a developmental and tissue-specific pattern. J. Invest. Dermatol. 102:622. (Abstr.)

7. Elenius, K., et al. 1991. Induced expression of syndecan in healing wounds. J. Cell Biol. 114:585-595.

8. Gallo, R.L., and Bernfield, M. 1996. Proteoglycans and their role in wound repair. In The molecular and cellular biology of wound repair. R.A.F. 
Clark, editor. Plenum Press. New York, NY. 475-492.

9. Ornitz, D.M., et al. 1992. Heparin is required for cell-free binding of basic fibroblast growth factor to a soluble receptor and for mitogenesis in whole cells. Mol. Cell. Biol. 12:240-247.

10. Rapraeger, A.C., Krufka, A., and Olwin, B.B. 1991. Requirement of heparan sulfate for bFGF-mediated fibroblast growth and myoblast differentiation. Science. 252:1705-1708.

11. Lyon, M., et al. 1998. Hepatocyte growth factor/scatter factor binds with high affinity to dermatan sulfate. J. Biol. Chem. 273:271-278.

12. Maimone, M.M., and Tollefsen, D.M. 1990. Structure of a dermatan sulfate hexasaccharide that binds to heparin cofactor II with high affinity. J. Biol. Chem. 265:18263-18271.

13. Mascellani, G., et al. 1993. Structure and contribution to the heparin cofactor II-mediated inhibition of thrombin of naturally oversulphated sequences of dermatan sulfate. Biochem. J. 296:639-648.

14. Cella, G., et al. 1992. Interaction between histidine-rich glycoprotein and platelet factor 4 with dermatan sulfate and low-molecular-weight dermatan sulfate. Angiology. 43:59-62.

15. Walker, A., and Gallagher, J.T. 1996. Structural domains of heparan sulphate for specific recognition of the C-terminal heparin-binding domain of human plasma fibronectin (HEPII). Biochem. J. 317:871-877.

16. Priglinger, U., Geiger, M., Bielek, E., Vanyek, E., and Binder, B.R. 1994 Binding of urinary protein $C$ inhibitor to cultured human epithelial kidney tumor cells (TCL-598). J. Biol. Chem. 269:14705-14710.

17. Dustin, M.L., Rothlein, R., and Bhan, A.K. 1986. Induction by IL-1 and interferon- $\gamma$ : tissue distribution, biochemistry, and function of a natural adherence molecule (ICAM-1). J. Immunol. 137:245-254.

18. Ihn, H., et al. 1994. Increased levels of circulating intercellular adhesion molecule- 1 in patients with localized scleroderma. J. Am. Acad. Dermatol. 31:591-595.

19. Sondergaard, K., et al. 1998. Soluble intercellular adhesion molecule-1 (sICAM-1) and soluble interleukin-2 receptors (sIL-2R) in scleroderma skin. Br. J. Dermatol. 37:304-310.

20. Majewski, S., et al. 1991. Expression of intercellular adhesion molecule1 (ICAM-1) in the skin of patients with systemic scleroderma. J. Invest. Dermatol. 97:667-671.

21. Furukawa, S., Imai, K., and Matusbara, T. 1992. Increased levels of circulating intercellular adhesion molecule- 1 in Kawasaki disease. Artbritis Rheum. 35:672-677.

22. Richard, L., Velasco, P., and Detmar, M. 1998. A simple immunomagnetic protocol for the selective isolation and long-term culture of human dermal microvascular endothelial cells. Exp. Cell Res. 240:1-6.

23. Chomczynski, P., and Sacchi, N. 1987. Single-step method of RNA isolation by acid guanidinium thiocyanate-phenol-chloroform extraction. Anal. Biochem. 162:156-159.
24. Mackay, F., Majeau, G.R., Hochman, P.S., and Browning, J.L. 1996. Lymphotoxin $\beta$ receptor triggering induces activation of the nuclear factor $\mathrm{\kappa B}$ transcription factor in some cell types. J. Biol. Chem. 271:24934-24938.

25. Delude, R.L., et al. 1994. CD14-mediated translocation of nuclear factor-kappa B induced by lipopolysaccharide does not require tyrosine kinase activity. J. Biol. Chem. 269:22253-22260.

26. Gallo, R.L., et al. 1994. Syndecans, cell surface heparan sulfate proteoglycans, are induced by a proline-rich antimicrobial peptide from wounds. Proc. Natl. Acad. Sci. USA. 91:11035-11039.

27. Subramanian, S.V., Fitzgerald, M.L., and Bernfield, M. 1997. Regulated shedding of syndecan- 1 and -4 ectodomains by thrombin and growth factor activation. J. Biol. Chem. 272:14713-14720.

28. Stratowa, C., and Audette, M. 1995. Transcriptional regulation of the human intercellular adhesion molecule-1 gene: a short overview. Immunobiology. 193:293-304.

29. Ziegler-Heitbrock, H.W.L., et al. 1993. Pyrrolidine dithiocarbamate inhibits NF-kB mobilization and TNF production in human monocytes. J. Immunol. 151:6986-6993.

30. Komatsu, S., Flores, S., Gerritsen, M.E., Anderson, D.C., and Granger, D.N. 1997. Differential up-regulation of circulating soluble and endothelial cell intercellular adhesion molecule-1 in mice. Am. J. Pathol. 151:205-214.

31.Jin, L., et al. 1997. The anticoagulant activation of antithrombin by heparin. Proc. Natl. Acad. Sci. USA. 94:14683-14688.

32. Kainulainen, V., Wang, H., Schick, C., and Bernfield, M. 1998. Syndecans, heparan sulfate proteoglycans, maintain the proteolytic balance of acute wound fluids. J. Biol. Chem. 273:11563-11569.

33. Oertli, B., Beck-Schimmer, B., Fan, X., and Wuthrich, R.P. 1998. Mechanisms of hyaluronan-induced up-regulation of ICAM-1 and VCAM-1 expression by murine kidney tubular epithelial cells: hyaluronan triggers cell adhesion molecule expression through a mechanism involving activation of nuclear factor- $\mathrm{KB}$ and activating protein-1. J. Immunol. 161:3431-3437.

34. Couchman, J.R., Caterson, B., Christner, J.E., and Baker, J.R. 1984. Mapping by monoclonal antibody detection of glycosaminoglycans in connective tissues. Nature. 307:650-652.

35. Yokoyama, Y., Ishikawa, O., and Miyachi, Y. 1997. Disaccharide analysis of skin glycosaminoglycan in localized scleroderma. Dermatology. 194:329-333.

36. Westergren-Thorsson, G., Coster, L., Akesson, A., and Wollheim, F.A. 1996. Altered dermatan sulfate proteoglycan synthesis in fibroblast cultures established from skin of patients with systemic sclerosis. J. Rheumatol. 23:1398-1406

37. Akimoto, S., Hayashi, H., and Ishikawa, H. 1992. Disaccharide analysis of the skin glycosaminoglycans in systemic sclerosis. Br. J. Dermatol. 126:29-34. 